Academic Journal of Social Sciences (AJSS)

Vol. 5, Issue 4 (October - December 2021) PP. 366 - 387

\title{
Investigating Job Performance through Empowering Leadership: A Mediating role of Goal Clarity and Self-Efficacy in the Telecommunication Sector
}

\author{
Waqar Ahmad ${ }^{1}$, Aneela Qadir ${ }^{2}$ and Muhammad Arshad ${ }^{3, *}$
}

\begin{abstract}
This study examines the relationship between empowering leadership and employees' job performance in Pakistan's telecom sector based on the leadership theory. The Telecom sector is suffering from a volatile situation; this demonstrates a lack of empowering leadership, which leads to the employees' job performance. Further, this study explores that goal clarity, and self-efficiency mediate between empowering leadership and employees' job performance. That explains the significance of these two mediators for this study's proposed model. These two variables strengthen the relationship between empowering leadership and employees' job performance. The data was collected from the employees of the Telecom sector of Pakistan. The survey was utilized to collect the information from 331 participants. Structural equation modeling technique was utilized through Smart PLS for analysis of data. Study results reveal that empowering leadership has a positive and significant relationship with the employees' job performance. Secondly, findings show that goal clarity and self-efficacy mediate empowering leadership and job performance. These two variables have a positive and significant relationship with empowering leadership and employees' job performance. This study also has potential implications for the organization's management to work on these aspects to improve the performance of their employees. This study is helpful for the other sectors for improving their performance. Companies' management should work individually and collectively for organization performance. This research contributes to the future research aspect for further analyzing these variables in other sector organizations to test this model. This research also provides direction to researchers to deeply analyze this proposed model by obtaining data through interviews or discourse analysis.
\end{abstract}

Keywords: Empowering Leadership; Self-Efficiency; Goal Clarity; Employees Job Performance; Pakistan

\footnotetext{
${ }^{1}$ School of Management Sciences and Economics, Kunming University of Science and Technology, Kunming, Yunnan, China.

2 School of Economics, Yunnan University of Finance and Economics, Kunming, Yunnan, China.

${ }^{3}$ Business School, Yunnan University of Finance and Economics, Kunming, Yunnan, China.

Corresponding Author: arshadtanoli8712@gmail.com
} 


\section{Introduction}

Management literature has gained special attention in empowering leadership. Employees have earned and enjoyed considerable autonomy in organizations through the healthy trend of empowerment (Naqshbandi, Tabche, \& Choudhary, 2019). Researchers have observed that leader empowerment has deeply affected employees' creativity by increasing the sense of autonomy between employees in an organization (Jaiswal \& Dhar, 2015). Empowered leaders hand over their authority to subordinates to make decisions according to requirements that directly help them improve innovative performance (Arshad, 2020). Leader empowerment stimulates the employees to seek, earn, and share knowledge mingled with information (Afsar, Badir, Saeed, \& Hafeez, 2017). In brief, empowering leadership means giving employees more autonomy (Gao \& Jiang, 2019). Empowerment also motivates employees to participate in decision-making, delegate responsibilities, and encourage team members to work together and independently without direct supervision (Gao \& Jiang, 2019). Researchers Humborstad, Nerstad, and Dysvik (2014) recount that the empowering of followers depends on the implementation of the goals of the Organization.

The limited literature on leadership empowerment and its relationship with employees' outcomes is available. Leaders and employees are confronted with myriad responsibilities to contribute to an organization's environmental sustainability (Ramirez, Gonzalez, \& Moreira, 2014). A positive relation has been demonstrated between empowering leadership and employee behavior towards its environment (Li, Liu, Han, \& Zhang, 2016). After the empowerment, it is also necessary for leaders to pay continuous responsiveness mingled with support organization and its innovative culture. The innovative culture brings, massive impact on employees' job crafting, which turns out to be new product development, as a requisite output of an organization in the market (Kim \& Beehr, 2020). Empowering leadership is akin to empowering employees with self-esteem, self-assurance, and self-efficacy; thus, employees take risks to solve problems and issues in strange ways (Kim \& Beehr, 2020). Empowering leadership and commitment to continuous improvement and innovation are associated with contextual ambidexterity (Van der Hoek, Groeneveld, \& Kuipers, 2018). Organizations now try to be ambidextrous at both levels of the organizational unit to the individual level (Mueller, Renzl, \& Will, 2020). Researchers also elaborate that organizations benefit from employee psychological empowerment and commitment (Kim, Beehr, \& Prewett, 2018), innovative work behavior (Arshad et al., 202 1). Also with, Job enthusiasm (Sariwulan, Agung, Sudrajat, \& Atmadiredja, 2019), work engagement (Bakker \& Albrecht, 2018). And mainly with, Organization's behavior (Haase, Hoff, Hanel, \& Innes-Ker, 2018), creativity (Arshad, 2020), psychological wellbeing (Clausen, Meng, \& Borg, 2019), task performance (Lee, Lyubovnikova, Tian, \& Knight, 2020), improved service only by empowering leadership (Li et al., 2016). Moreover, Kim and Beehr (2020) posit that employees' degree of autonomy is enhanced by empowering leadership. Concerning its content, performance shows the relationship between expected output and results achieved (effectiveness), effective and

minimal cost (economy), effective cost, and the perceived result efficiency (Andrews \& Van de Walle, 2013). Employees' work output is significant for organizational growth and development and empowering leadership (Clausen et al., 2019). 
In service sector organizations, the performance of employees is the decisive factor for healthy growth and development. Further, it enhances the quality standards of the services for the consumers when an interaction takes place with them (Ostrom et al., 2010). After the empowerment, leaders who involve themselves in decision-making enhance the employee's ability and provide more chances to learn and stimulate them to perform well (Choi, Goh, Adam, \& Tan, 2016). Employees' performance quality affects too much when too much adherence to rules and regulations occurs (Bulgurcu, Cavusoglu, \& Benbasat, 2010). There is a general recognition of how individuals react to leadership behavior in organizations that play a vital role. In contrast, low leadership empowerment gives a limited opportunity for employees' autonomy and discourages self-management abilities ( Kim \& Beehr, 2017). Therefore, it deduces that the more leadership empowerment, the more influence employee's job performance.

Leadership empowerment agrees on goal clarity by increasing natural motivation and psychological ownership of the goal (Kundu, Kumar, \& Gahlawat, 2019). However, leadership empowerment cultivates goal clarity by building the follower's motivation level and psychological ownership of their job performance (Gonzalez-Mulé, Courtright, DeGeest, Seong, \& Hong, 2016). Leaders' kind of behavior gives followers impetus to internalize the objectives. However, if communal empowering leadership is exhibited with a lopsided emphasis on letting go of control. There will be a problem in coordination; if leaders blindly encourage employees' autonomy and self-determination (Oswald et al., 2018). Goal clarity draws followers' guidelines and helps them focus on the objective (Abro, Siyal, Souayeh, \& Atangana, 2020; Caillier, 2016b). Thinking self-efficacy is a type of self-assurance or a specific task kind of self-esteem (Jaaffar, Ibrahim, Rajadurai, \& Sohail, 2019). There are three dimensions of self-efficacy: strength, the belief concerning magnitude as weak or strong, magnitude, the difficulty of a task person believes, generality, the extent to which the projection is generalized throughout the situation (Gist, 1987). An employee's ability influences his performance and motivation level (Beattie, Woodman, Fakehy, \& Dempsey, 2016). Traits like self-compassion (Nalipay \& Alfonso, 2018) and dimensions of determination have connected to expanding career exploration and development of employees' talent in an organization (Datu, Yuen, \& Chen, 2017). Employees seldom carry out the task when the output seems to be abortive. Employees feel efficacious when leaders use their empowering behavior with their subordinates. Employees get emotional support and words mingled with encouragement, which results in a higher level of self-efficacy.

Therefore, it is assumed that goal clarity and self-efficacy mediate between empowering leadership and employees' job performance (Datu et al., 2017; Hoffmann \& Plotkina, 2021). So, the effective implementation of empowering leadership with mediating variables, goal clarity, and self-efficacy is considered a very dynamic and challenging area of research. Especially to evaluate employees' job performance containing employees of the telecom sector (Tang, Zhang, \& Wang, 2020); findings suggest that leaders' empowering behaviors each day strongly affect employees' day-to-day job crafting with high vigor. The current study's main contribution to the literature of leadership theory is indifferent means; firstly, it investigates the relationship between empowering leadership and job performance. Secondly, it explores how goal clarity and self-efficacy mediate between empowering leadership and job performance. 


\section{Literature Review and Hypotheses Development}

\subsection{Empowerment Leadership}

Empowerment has been a trendy study area (Humborstad et al., 2014). Although various authors described empowerment as empowering other people, they further define this concept as the internal processes of the employee being empowered (Humborstad et al., 2014). (Kim \& Beehr, 2020). It is an agreement in the literature that empowered employees are mentally characterized by psychological empowerment. It has been defined as an intrinsic level of motivation shown in four perceptions like meaning, competence, self-determination, and its impact (Olafsen, Halvari, Forest, \& Deci, 2015). The empowerment concept emergence is from employee involvement and participative management theories (Kundu et al., 2019).

Many researchers have recognized that the sense of autonomy among employees has increased because of empowering leadership (He \& Long, 2018). Empowering leadership gives excellent impetus to employees to seek knowledge and share it with others (Menguc, Auh, \& Uslu, 2013). In brief, empowering leadership means giving employees more autonomy. Empowering leaders play a role in encouraging employees to participate in decision-making, delegate responsibilities, and promote team coordination among employees (Kundu et al., 2019). Further researchers describe that a positive empowering of followers is determined by implementing organizational goals (Lee, Willis, \& Tian, 2018). Consequently, the followers' empowerment can have negative consequences if the employees and the Organization have different objectives (Kundu et al., 2019).

Several researchers define empowering leadership as a method of sharing authority and delegating autonomy and duties to followers, teams, or collectives through a specific set of leadership behaviors for employees to improve internal motivation and productivity (Li et al., 2019). In line with a stream of supporting leadership (Bowers \& Seashore, 1966), chronological creation for the principle of motivating leadership has been; coaching, delegating behaviors including situational leadership theory (Stewart \& Gapp, 2017). Also, participative leadership (Chan, 2019), super leadership(Georgianna, Müller, Schermelleh-Engel, \& Petersen, 2016), and individualized leadership that emphasizes the importance of followers' self-worth (Kim et al., 2020).

Researcher Kim et al. (2018) began to believe that empowering leadership may help to increase cognitive job demands. They enlightened that these results from increased responsibility and problem-solving by the empowering leader to followers. Furthermore, they have argued that empowering leaders has increased employees' job resources, and the combination of increased resources and demands has increased employees' work engagement. Based on this, it is possible that empowering leadership leads to a process that can change feelings of stress into feelings of energy and interest in the activities (Kundu et al., 2019).

He argued that the purpose of empowering leadership is to teach employees selfleadership skills. Authors have also argued that learning new things, developing their abilities and skills, and carrying out new responsibilities, do this. Consequently, empowering leadership 
is a leadership style, which may be suitable for an academic setting, considering how academics perceive leadership in their workplace.

\subsection{Empowering Leadership and Employees' Job Performance}

Empowering leadership is defined as outlining practices to share power with their juniors (Srivastava, Bartol, \& Locke, 2006). Its manner to establishing the environment which makes it conceivable the share of power to subordinates, by defining the importance the role of subordinates, involved him in decision making, according to the current situation give them the freedom to act and perform, and demonstrating trust in the potential of the employees (Afsar \& Masood, 2018). Furthermore, employees' productivity is crucial for organizational growth and performance and empowering leadership, most explicitly for an organization with service (Chow, 2018; Martin, Liao, \& Campbell, 2013). They empower leadership in decision-making, and connected accountability increases employee meaning sense, giving them learning opportunities and leading them to thrive for work (Kim \& Beehr, 2020). It has been noted that the employees cannot perform their duties at an ideal level without monitoring or autonomy. Too much obedience to rules and regulations badly affects the quality of employees' service (Kundu et al., 2019). On the other hand, there's an extensive appreciation that individual and organizational factors play an essential role in reacting to leadership behaviors (Shanafelt \& Noseworthy, 2017). In this situation, empowering leadership may well develop as a vital variable, which can proactively be essential for the performance of employees' jobs.

Several types of research have empirically braced the direct or indirect empoweringleadership connection with employees' job performance (Byun, Lee, Karau, \& Dai, 2020; Hao, He, \& Long, 2018; Kundu et al., 2019). Even though there is a positive relationship between empowering-leadership employees' job performance, it has been advised that leaders need to be careful however exhibiting empowering manners. The task was challenging (Li et al., 2016).

As a result, based on the previous research, the following hypothesis is offered that is mentioned below:

H1: Empowering leadership positively influences the employee's job performance

\subsection{Empowering Leadership, Goal Clarity and Employees' Job Performance}

Empowering leadership fosters a sense of ownership and self-determination that might take the place of great consideration to organizational and team goals (i.e., seen as personal goals with increased empowerment) (Kearney et al., 2019). On the other hand, only group empoweringleadership has placed an uneven emphasis on letting go of mechanism. Fellow employees may still act in inconsistent ways with the leader's expectations. Leaders who owlishly promote subordinates' self-determination and autonomy risk causing or exacerbating teamwork problems (Gayle et al., 2011; Kim \& Park, 2020).

The participatory influence of empowering leadership is the conception of goal clarity and its guiding and inspiring impact on staff's job performance. Goal clarity refers to how informed followers' daily problems relate to higher-level goals (Gonzalez-Mulé et al., 2016; Hoffmann \& Plotkina, 2021). While a more recent study has identified some characteristics of goal clarity that 
may lead to underperformance, the findings from earlier studies remain useful (Chamberlin, Newton, \& LePine, 2018).

The interactive impact theory of empowering leadership defines goal clarity and its driving and motivating effect on employee work performance (E.-J. Kim \& Park, 2020). Goal clarity is defined as the degree to which followers are attentive to how their normal problems contribute to achieving more significant objectives (Zheng, Li, Brad Harris, \& Liao, 2019). Although more contemporary research has also revealed some aspects of goal clarity (GonzalezMulé et al., 2016).

The literature on evaluating employee job performance has two approaches: one is the objective method, which focuses on the results of the job, and the other is the subjective approach, which focuses on the employees' execution of job duties rather than the results of job activities (Darvishmotevali \& Ali, 2020). It was discovered that workers frequently only have control over their work assignments, not the employment outcomes. The subjective measure is more acceptable in such cases than the objective measure of job performance (Yilmaz, 2015). One form of leadership that demonstrates a recommended approach is "Empowering Leadership," which established a positive association through performance outcomes, such as employees' workrelated wellbeing and improved attitudinal and behavioral consequences (Chiniara \& Bentein, 2016).

Similarly, a researcher explains that reinvention reforms in an organization clarify goals for the employees and ultimately improve the employees' performance. Another study in the Dutch public sector identified that goal clarity is the most crucial factor for team performance (Song et al., 2020). However, the author suggests this comprehensively in future directions (Van der Hoek et al., 2018). A clear organizational goal also leads an organization to team performance (Gonzalez-Mulé et al., 2016). So, it is assumed from the above arguments that goal clarity and empowering leadership are based on the employees' job performance. We revealed the following hypothesis based on the preceding arguments of the researchers.

H2: Empowering leadership positively influences goal clarity.

H3. Goal clarity is a link with the employees' job performance.

\subsection{Empowering Leadership and Employees' Job Performance mediated by Goal Clarity}

Goal-clarity is a resource of job that makes employees' tasks more comprehensive and straightforward. According to the characteristic model of a job by the vital job, characteristic represents by goal clarity which has a significant impact on employee's wellbeing and motivation (Caillier, 2016a). Goal clarity indirectly affects job performance through empowering leadership. Moreover, the clarity of goal is a level in which the follower understands their objectives and what they should achieve (Caillier, 2016b). Managers use production-oriented leadership to try at the workplace to ensure goal attainment of the employees' (Shanafelt \& Noseworthy, 2017). It might involve the managers' communication of their expectations, responsibilities, and how employees reach their goals. When employees have this clarity, they also can respond and act 
according to these goals and expectations; hence, they can deal with the condition and enhance their control (Gruman \& Saks, 2011).

Goal clarity directs sub-ordinates attention and focuses on what is related (Caillier, 2016b). Because of the lack of objective clarification, subordinates can be distracted or abstracted by events that are irrelevant to the overall goals and do not pay for success on their job (Caillier, 2016b). Researchers discovered a positive association between the objective clarity of individual subordinates' outcomes. (Caillier, 2016b; Hu \& Liden, 2011). We've also suggested that goal clarity is a mechanism based on the logic described above, clarifying how empowering-leadership activities complement each other in predicting employee work performance. Goal clarity, we propose, affects the synergistic interactive influence of empowered leadership on employee job performance. As an outcome of the above discussion, the proposed the following hypothesis:

H4. In the relationship between empowering leadership and job performance, goal clarity is a mediator.

\subsection{Empowering Leadership, Self-Efficacy and Employees' Job Performance}

The Empowering-leadership exercises its effect on the work role performance of employees by enhancing the self-efficacy of followers or the "belief in one's capabilities to organize and execute the courses of action necessary to attain specified results (Beattie et al., 2016; Zimmerman, 2000). Their research on empowerment theory clarified that empowerment is a motivational build. It suggested that empowerment means a "process whereby the individual's belief in his or her self-efficacy is boosted" (p. 474). They have specifically projected five steps of the empowerment process, describing how this motivational construct is related and works. The first stage is the diagnosis of situations within the Organization guilty of powerless feelings among subordinates. The second stage is the use of empowering strategies by the leader. In the third stage, three techniques have been implemented to disseminate self-efficacy info to a subordinate. Subordinates improve their efficacy beliefs in stage four, the last behaviorally influenced by this stage.

Generalized self-efficacy believes that someone can achieve their objectives in different tasks and situations (Kim \& Beehr, 2017). Self-efficacy brings the employees' creative behavior and removes the wicked working behaviors in the task performance (Arshad et al., 2021). Leaders give them full courtesy, courage, and confidence over their ability In the view of Social cognitive theory, self-efficacy can be increased by verbal encouragement, by task or skill accomplishment, and through the process of observational learning (Schunk \& DiBenedetto, 2020). These can be helpful for job performance through leaders' guidance and feedback and witnessing their supervisor's work (e.g., vicarious learning). Self-efficacy is attached to the empowerment process, which is explored theoretically, which explains a positive and significant relationship between empowering leadership and subordinates through the mediation of self-efficacy. Empowering leadership encourages and stimulates followers to participate in the decision-making process, then there creates a lot of opportunities for knowledge sharing and learning with a collaboration with each other (Latham et al., 1994). Self-efficacy is affected by all these processes.

Furthermore, directly empowering leaders should have information about their followers' 
abilities and capabilities and further can use these skills for the beliefs of self-efficacy (Kim \& Beehr, 2017). According to the expectancy theory of motivation, suppose an employee is strongly committed to achieving the Organization's tasks. In that case, it overlays the way for the better performance of the employees. Who thinks about their job's efficacy through positive work behavior has to an organization's ultimate performance. As a result, there is a positive relationship between self-efficacy and job performance (Qiu, Hu, Xu, \& Li, 2015).

In the above literature, we assumed that empowering leadership would increase employees' self-efficacy, strengthening and improving the employees' job performance. As a result, we offered the following hypothesis based on the preceding arguments:

H5. Empowering leadership is positively linked with self-efficacy.

H6: Self-Efficacy has a positive association with employees' job performance.

\subsection{Empowering Leadership and Employee's Job Performance mediated by Self- Efficacy}

According to Ebner, Schulte, Soucek, and Kauffeld (2018), self-efficacy has a motivational role in achieving the Organization's goals. Further, empowerment has been defined as "a process of enhancing feelings of self-efficacy among organizational members through the identification of conditions that foster powerlessness through their removal by both formal organizational practices and informal techniques of providing efficacy information" (p. 474). Self-efficacy mentions an ability of an individual to perform a particular behavior or control one's environment successfully (Schwarzer \& Warner, 2013). In this way, empowerment is a process that helps empower the followers in an organization (Zhu, Sosik, Riggio, \& Yang, 2012).

According to that, empowered employees feel that they can accomplish their task at the best level of knowledge, influencing their task initiation and persistence. Furthermore, Afsar and Masood (2018) have stated that leaders who show empowering behaviors can quickly increase the employees' self-efficacy (Afsar \& Masood, 2018). Beattie et al. (2016) has mentioned that selfefficacy can be improved with the help of positive behavior and emotional support, positive words of encouragement, a role model of successful people and by models of success with whom people identify, and the experience of understanding about to achieve a task (Arshad et al., 2021). Accordingly, a leader is involved in empowering the behaviors of their subordinates; in this way, subordinates would be motivated for their job performance due to support, encouragement, and guidance from their supervisor. In the past studies researchers, empirical work explored that empowering leadership has a positive association with self-efficacy (Gao \& Jiang, 2019), team efficacy (Srivastava et al., 2006), creative self-efficacy (Haase et al., 2018), and career self-efficacy (Gao \& Jiang, 2019). That explains that the self-efficacy of the followers could help and lead to increasing the job performance level of the employees at the workplace. Past studies' literature explored that self-efficacy is positively related to job performance (Beattie et al., 2016).

Past studies explain that empowering leadership enhances employees' self-efficacy to increase their performance. That suggests the intervening role of self-efficacy for empowering leadership has a positive association with job performance. (Beattie et al., 2016). Furthermore, it 
explains that self-efficacy is linked to empowering leadership and job performance. Thus, we assumed our hypothesis as:

H7. Self-efficacy strengthens the association of empowering leadership and job performance.

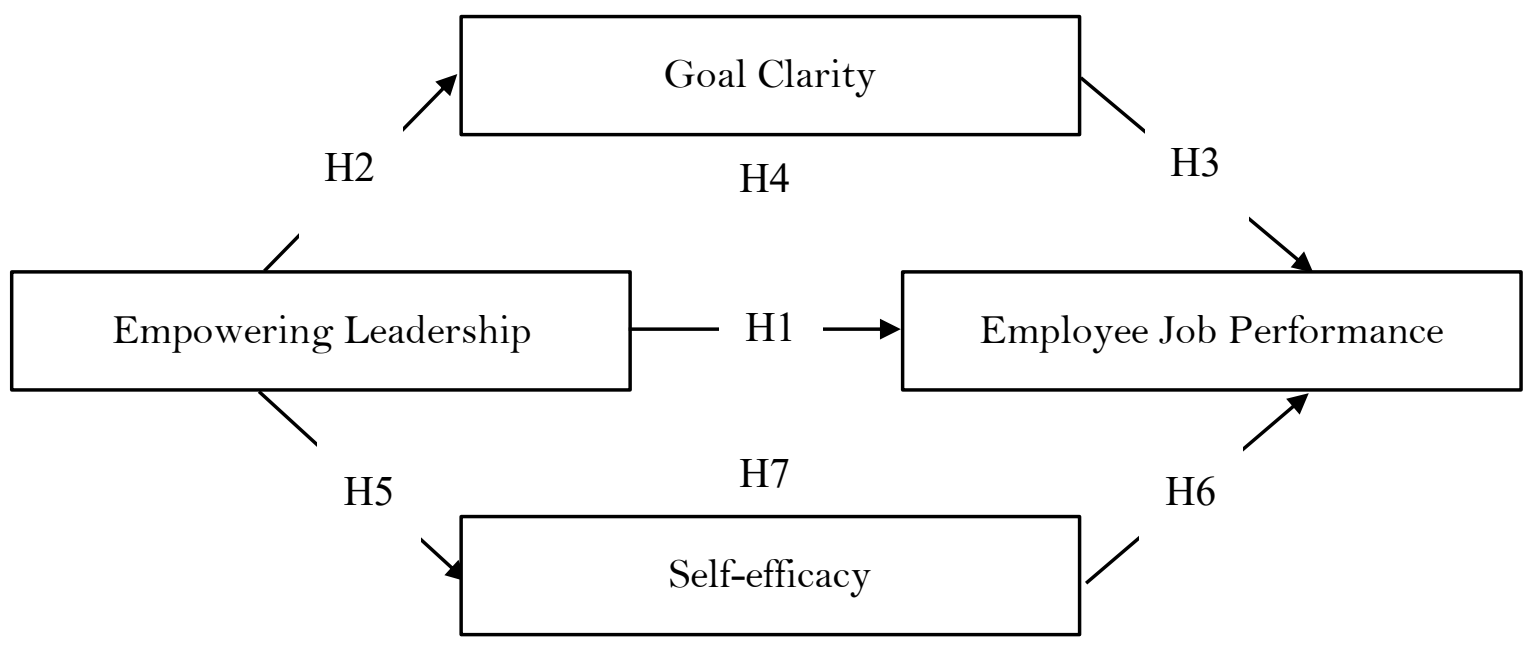

Figure 1: Theoretical Framework

\section{Materials and Methods}

\subsection{Participants and Procedure}

This study used a survey-based technique with multiple questions to empower leadership, goal clarity, self-efficiency, and job performance. A sample of data has been collected from telecom companies like Pakistan Telecommunication Limited (PTCL), Zong, Telenor, Jazz, and Warid working in Pakistan. A cross-sectional technique has been used for data collection.

The current study proposed model and hypotheses were tested by collecting data through a survey method. The measurement scale was adapted from the existing literature and tested scale. In the words and sentences of the items, minors' modifications have been carried out. The study respondents have been worked on different posts like HR managers, finance managers, communication officers, middle and lower-level management employees. Four research assistants were hired for the data collection process. Four research experts have given the questionnaire finalizing the process for the instruments' face and content validity. After the experts' comments and the discussion process, a pilot study was carried out. A total of 40 questionnaires have been distributed, 30 participants gave their feedback. The Cronbach's alpha value was 0.87. A model fitness test was also carried out $\chi^{2} / \mathrm{df}$ is 2337.53 and $\mathrm{CFI}=0.92, \mathrm{NFI}=0.88, \mathrm{GFI}=0.95$, and RMSEA $=0.0 .65$, which shows a strong model. Furthermore, all the processes were checked for the measurement model. After the pilot study, 431 questionnaires were distributed to different employees of the companies. A purposive sampling technique was used for the selection of the participants. It has ensured the participants that their identity will be anonymous anonymity will 
be under research ethics. Their responses will not be misused. Only 331 useable and recordable questionnaires have been received.

One hundred incomplete questionnaires were received, which were removed from the study. The response rate remained 77\%. Due to COVID-19, the response rate was recorded low. A five-point Likert scale (from $1=$ strongly agree, strongly disagree $=5$ ) was employed in the questionnaire. A totalled of $331,65 \%$ of respondents were male, and $35 \%$ were male. The respondents' qualification were Bachelor (44.5\%) master $(40.5 \%)$ and $\mathrm{PhD}(15 \%)$. Participants were working in different Telecom companies in Pakistan, including PTCL (30\%), Zong (26\%), Jazz (24\%), and Warid (20\%). Three directors, 2 HR managers, three finance officers, two marketing managers, three communication officers, 318 filed officers, coordinators, and salesman, recorded their responses from these companies. The majority of the responses came from the middle-level employees working at the office and field level. The top management response was $4 \%$, and lower-level employees were $96 \%$.

\subsection{Scale Measurement}

Empowering Leadership. Five-point Likert-type scales were used to assess empowering leadership. The scale was composed of eight items developed and validated by the researchers (Kirkman \& Rosen, 1999). This scale has also been used by (Amundsen \& Martinsen, 2015). Cronbach's alpha was 0.85 , which is a good result.

Employees' Job Performance. Job performance has been measured with a five-item scale developed by (Na-Nan, Chaiprasit, \& Pukkeeree, 2018). The value of Cronbach's $\alpha$ was 0.87.

Goal Clarity. The five items derived from the (Hu \& Liden, 2011) study were used to assess goal clarity. The Cronbach's $\alpha$ value was 0.91 . The sample indices statements are like that "In our research/project group; we are committed to pursuing our research/project collaboration goals." Furthermore, "In our research/project group, we enthusiastically pursue collective goals."

Self-Efficiency. Creative self-efficacy was evaluated by (Bandura, 2006) with eight items. The researchers assess these items. The example item, "I have enough knowledge and confidence in making my task easier." We use five-point Likert scales to collect data. This variable had a Cronbach's alpha of 0.72 .

Control Variables. Age, gender, organizational age, and employees' experience at the participant level were included as control factors in this study. All of these factors were included as control variables in this study. It might have related to goal clarity, self-efficacy, and performance.

\section{Results}

The current study has used SmartPLS modeling for structural equation modeling. SmartPLS is structural equation modeling (SEM) is a powerful technique for modeling structural equations ideal for exploratory models and small-sized datasets. The analysis has been done using SmartPLS 3.2.3. SmartPLS SEM modeling has been used for the analysis of the model. 


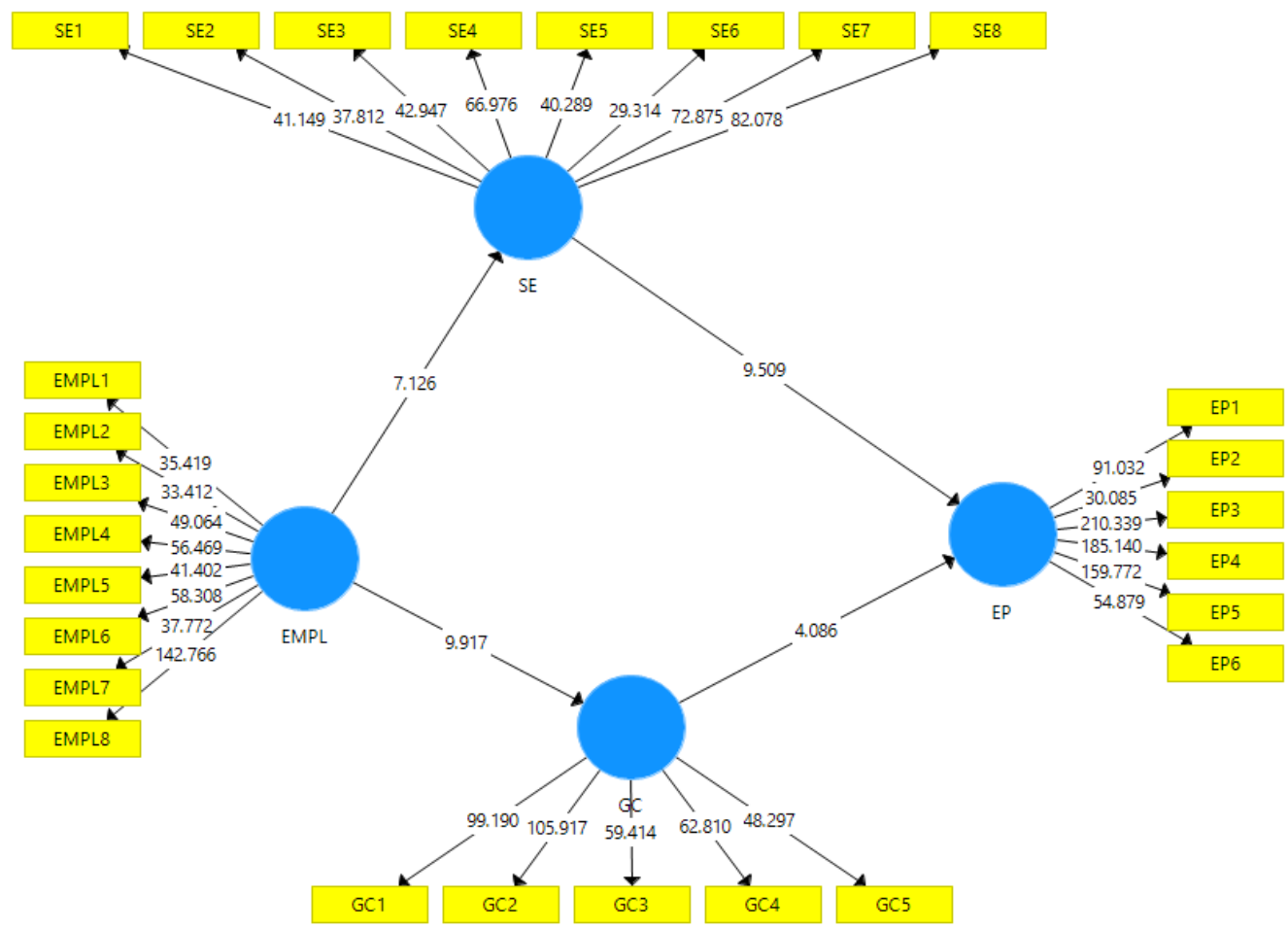

Figure 2: Bootstrapping Analysis of the Study Variables

Figure 2 explains the association of the independent variable (empowering leadership) to the dependent variable (employees' job performance). Furthermore, self-efficacy and goal clarity play the mediating variables; these variables' relationship with the independent variable and dependent variables (employees' job performance) explains that these two variables play a role in strengthening the relationship between these two variables.

Table 1: Inter-correlation among the Constructs

\begin{tabular}{lllll}
\hline & EMPL & EP & GC & SE \\
\hline EMPL & $\mathbf{0 . 8 6 3}$ & & & \\
EP & 0.484 & $\mathbf{0 . 7 2 0}$ & & \\
GC & 0.547 & 0.695 & $\mathbf{0 . 7 4 0}$ & \\
SE & 0.384 & 0.794 & 0.673 & $\mathbf{0 . 8 7 4}$ \\
\hline
\end{tabular}

Table 1 shows inter-correlation among the variables. The inter-factor correlations were lower than the required limit of 0.75 , indicating no difficulty with multi-collinearity issues (Hair Jr, Sarstedt, Ringle, \& Gudergan, 2017).

\subsection{Common Method Variance Bias Test}

The Common method variance (CMV) bias is noteworthy for the data variance analysis. CMV mostly took the question about data gathered from only one source. According to Harman 
(1976), a single test was executed to determine CMV determination within studied variables. The statistical test was performed to determine the presence of CMV among study variables. CMV results demonstrated that all the indices of the study were divided into four constructs and the first construct showed a total variance of $32.41 \%$, which was lesser than the $41 \%$ (Hair Jr et al., 2017).

Additionally, the study performed a complete collinearity examination in SmartPLS. Several social science scholars proposed and implemented the reliable and contemporary approach (Kock, 2015). All the values of the VIF are less than the threshold value of 3.3, which specifies that in the current study model, there is no such problem of CMO (Kock, 2015).

\subsection{Validity and Reliability}

The current research examined the validity and reliability of the study data. The factors loading values were higher than the threshold value of 0.70. Cronbach alpha, AVE, CR, and Cronbach alpha, have been calculated to confirm convergent validity. Table 2 illustrates the CR results: the values from 0.86 to 0.96 , greater than the threshold value 0.70 , and the values of Cronbach alpha in between 0.947 to 0.974 , greater than the standard value 0.70 described the threshold value of AVE as 0.50. In Table 2, all AVE values are calculated from 0.60 to 0.83.

Discriminant validity has been determined as per the standards recommended by (Lix \& Sajobi, 2010). That permits inter-correlation between concepts, and the square root of AVE of the construct has been compared to check the discriminant validity. AVE's square of root value greater than inter-correlations between propositions demonstrates decent discriminant validity.

Table 3 results show that the value of $\mathrm{CR}>0.7$ and $\mathrm{AVE}>0.5$ which confirm convergent validity. It means that we can move to the mediation effect of goal clarity and self-efficiency for study. According to Table 3, empowering leadership positively correlates with goal clarity. Again, there is a positive and significant association between empowering leadership and selfefficiency. Further, Table 4 also illustrates a positive and statistically significant relationship between goal clarity and employee job performance. Lastly, Table 3 shows that self-efficiency is positively related to the employee's job performance. From Table 4 results, it has been clear that all the five hypotheses have been supported in this study.

With t-values of 3.635 and 5.233, the bootstrapping analysis revealed that all three indirect effects, $\beta=0.044$ and $\beta=0.044$, are significant. The indirect effects $95 \%$ Boot CI Bias Corrected: $[\mathrm{LL}=0.049, \mathrm{UL}=0.2711]$, and $[\mathrm{LL}=0.136, \mathrm{UL}=0.350]$ do not straddle a $\mathrm{O}$ in between showing a mediation between the independent and dependent variables (Preacher and Hayes, 2004; 2008). We can conclude that mediation effects are statistically significant in this case. The mediation analysis results are given in Table 4. 
Table 2: Construct Reliability and Validity

\begin{tabular}{|c|c|c|c|c|c|c|}
\hline & Indicators & $\begin{array}{c}\text { Factor } \\
\text { Loading }\end{array}$ & $\begin{array}{c}\text { Cronbach } \\
\text { 's Alpha }\end{array}$ & rho_A & $\begin{array}{l}\text { Composite } \\
\text { Reliability }\end{array}$ & $\begin{array}{l}\text { Average Variance } \\
\text { Extracted (AVE) }\end{array}$ \\
\hline \multirow{8}{*}{$\begin{array}{l}\text { Empowering } \\
\text { Leadership }\end{array}$} & EMPL1 & 0.806 & \multirow{8}{*}{0.95} & \multirow{8}{*}{0.958} & \multirow{8}{*}{0.958} & \multirow{8}{*}{0.74} \\
\hline & EPML2 & 0.831 & & & & \\
\hline & EMPL3 & 0.873 & & & & \\
\hline & EMPL4 & 0.876 & & & & \\
\hline & EMPL5 & 0.837 & & & & \\
\hline & EMPL6 & 0.883 & & & & \\
\hline & EMPL7 & 0.868 & & & & \\
\hline & EMPL8 & 0.925 & & & & \\
\hline \multirow{6}{*}{$\begin{array}{l}\text { Employee } \\
\text { Performance }\end{array}$} & $\mathrm{P} 1$ & .0 .944 & \multirow{6}{*}{0.968} & \multirow{6}{*}{0.970} & \multirow{6}{*}{0.92} & \multirow{6}{*}{0.86} \\
\hline & $\mathrm{P}_{2}$ & .0 .824 & & & & \\
\hline & P3 & .0 .967 & & & & \\
\hline & $\mathrm{P}_{4}$ & .0 .970 & & & & \\
\hline & $\mathrm{P} 5$ & .0 .960 & & & & \\
\hline & P6 & .0 .902 & & & & \\
\hline \multirow{5}{*}{ Goal Clarity } & $\mathrm{GC} 1$ & .925 & \multirow{5}{*}{0.941} & \multirow{5}{*}{0.947} & \multirow{5}{*}{0.84} & \multirow{5}{*}{0.83} \\
\hline & $\mathrm{GC} 2$ & .947 & & & & \\
\hline & GC3 & .890 & & & & \\
\hline & $\mathrm{GC}_{4}$ & .902 & & & & \\
\hline & GC5 & .879 & & & & \\
\hline \multirow{8}{*}{$\begin{array}{c}\text { Self- } \\
\text { Efficiency }\end{array}$} & $\mathrm{SE} 1$ & .859 & \multirow{8}{*}{0.933} & \multirow{8}{*}{0.936} & \multirow{8}{*}{0.96} & \multirow{8}{*}{0.76} \\
\hline & $\mathrm{SE} 2$ & .850 & & & & \\
\hline & SE3 & .873 & & & & \\
\hline & SE4 & .902 & & & & \\
\hline & SE5 & .862 & & & & \\
\hline & SE6 & .806 & & & & \\
\hline & SE7 & .914 & & & & \\
\hline & SE8 & .923 & & & & \\
\hline
\end{tabular}

Table 3: Path Coefficient

\begin{tabular}{lccccc}
\hline & $\begin{array}{c}\text { Original } \\
\text { Sample (O) }\end{array}$ & $\begin{array}{c}\text { Sample Mean } \\
(\mathbf{M})\end{array}$ & $\begin{array}{c}\text { Standard Deviation } \\
(\mathbf{S T D E V})\end{array}$ & $\begin{array}{c}\text { T Statistics } \\
(\mid \mathbf{O} / \text { STDEV } \mid)\end{array}$ & $\begin{array}{c}\text { P } \\
\text { Values }\end{array}$ \\
\hline EMPL-> & 0.547 & 0.550 & 0.055 & 9.917 & 0.000 \\
GC & & 0.386 & 0.054 & 7.126 & 0.000 \\
EMPL -> & 0.384 & 0.293 & 0.072 & 4.086 & 0.000 \\
SE & 0.294 & 0.597 & 0.063 & 9.509 & 0.000 \\
GC -> EP & 0.596 & & & & \\
SE -> EP & & & & &
\end{tabular}

Table 4: Confidence Interval Bias

\begin{tabular}{lccccc}
\hline & Original Sample $(\mathbf{O})$ & Sample Mean $(\mathbf{M})$ & Bias & $\mathbf{0 . 5 \%}$ & $\mathbf{9 9 . 5 \%}$ \\
\hline EMPL -> GC -> EP & 0.161 & 0.162 & 0.001 & 0.049 & 0.271 \\
EMPL -> SE -> EP & 0.229 & 0.231 & 0.002 & 0.136 & 0.350 \\
\hline
\end{tabular}


Table 5 demonstrated a significant positive relationship between empowering leadership, goal clarity, self-efficacy, and employees' performance. Furthermore, Table 5 illustrated that goal clarity and self-efficacy are mediators for empowering leadership and employees' job performance.

Table 5: Hypotheses Testing on Mediation

\begin{tabular}{ccccccc}
\hline No & Relationship & $\begin{array}{c}\text { Standard } \\
\text { Deviation } \\
(\text { STDEV })\end{array}$ & $\begin{array}{c}\text { T Statistics } \\
(\mid \mathbf{O} / \text { STDEV } \mid)\end{array}$ & LL & UL & Decision \\
\hline $\mathrm{H} 6$ & $\begin{array}{c}\text { EMPL -> GC } \\
->\text { EP }\end{array}$ & 0.044 & $3.635^{* *}$ & 0.049 & 0.271 & Supported \\
H7 & $\begin{array}{c}\text { EMPL - SE } \\
->\text { EP }\end{array}$ & 0.044 & $5.233^{* *}$ & 0.136 & 0.350 & Supported \\
\hline
\end{tabular}

\section{Discussion}

This study proposed seven hypotheses to explore the impact of empowering leadership, goal clarity, and self-efficiency on job performance. H1 shows that empowering leadership positively and significantly affects job performance. Study results proved that job performance depends on empowering leadership (Jada \& Mukhopadhyay, 2019; Jamal \& Ali, 2017; O'Donoghue \& Van der Werff, 2021). Hence, H1 has proved that empowering the telecom sector is necessary for the employees' job performance. H2 shows that empowering leadership predicts goal clarity. The results show that empowering leadership provides the foundation for improving the goal clarity of Telecom sector employees. So, study H2 supported. These results link to the study of (Farhan, 2017; Kim et al., 2018).

The study's H3 reveals that goal clarity is positively associated with job performance. The results confirmed that goal clarity strengthens job performance; also, Goal clarity motivates employees to improve their job performance (Le \& Nguyen, 2020; Patanakul, Pinto, \& Pinto, 2016). Study findings explain that goal clarity has positive with job performance. It means goal clarity paves the way for the employees' job performance in the telecom sector. H4 predicts that empowering leadership affects self-efficacy. According to the study's findings, empowering leadership has a statistically significant and positive relationship with self-efficacy. As a result, H4 was supported. These results are consistent with (Hao et al., 2018; Ma, Cheng, Ribbens, \& Zhou, 2013). H5 suggests a link between self-efficacy and job performance. According to the results, Self-efficacy is good and has a considerable impact on job performance. It means that employees with more self-efficacy perform better at work. So, our H5 is supported. H6 shows and confirms that goal clarity plays an intervening role in empowering leadership and job performance. According to the study's findings, goal clarity can strengthen the connection between empowering leadership and job performance. Hence the study supported H6. These results are linked with the work of (Hoffmann \& Plotkina, 2021; Hu \& Liden, 2011).

Finally, it has also confirmed that self-efficacy plays a mediator role between empowering leadership and job performance. The study's findings have shown that empowering leadership improves job performance when self-efficacy is present as a mediator. Hence, the $\mathrm{H} 7$ of the study 
is approved. These results match (Zahra, Ahmad, \& Waheed, 2017).

\section{Theoretical Implications}

The primary study contribution is that it adds new literature to the existing body of knowledge. This study's most important contribution is that it mainly focuses on the individual rather than the organizational level, such as self-efficacy and goal clarity, missing in previous studies. This study extended the previous researchers' work who only work on the relationship empowering leadership, job satisfaction, self-leadership, and psychological empowerment (Amundsen \& Martinsen, 2015). And employee goal orientation and work performance (Humborstad et al., 2014), employee work performance, passion for work, and breadth selfefficiency (Hao et al., 2018), task performance (Lee et al., 2020), job performance, psychological empowerment (Kundu et al., 2019) and psychological wellbeing and job engagement (Clausen et al., 2019). The latest research expanded on the work of previous scholars (Hao et al., 2018).

The study results also confirmed the employees' job performance by improving empowering leadership, goal clarity, and self-efficiency and extended previous researchers' work (Hao et al., 2018). That research explains that empowering leadership is not the only factor affecting employees' job performance. Still, this relationship is based on goal clarity and selfefficacy between empowering leadership and employees' job performance.

\section{Practical Contribution}

Although this study has a theoretical contribution, it also has several practical implications for its managers. When the Organization's management implements empowering leadership, managerial staff should be aware of its implementation conditions. Furthermore, we discovered that self-efficiency strengthens the link between empowering leadership and job

performance. Hence, top management can improve the employees' self-efficacy and goal clarity by giving them a role, training, coaching, and enlarging their jobs (Ebner et al., 2018). Secondly, goal clarity has a statistically significant and positive association with empowering leadership and job performance (Harris, Li, Boswell, Zhang, \& Xie, 2014). Managers in an organization can increase the efficiency of the employees by giving them clear goals. This study has contributed to the employees' performance, and ultimately, it affects the organization's productivity. Telecom sector companies should focus on goal clarity to meet the current competitive environment.

\section{Limitation and Future Direction}

The current work contributes to the current body of knowledge, but still, this study suffers from several limitations. Firstly, the most obvious shorting is that the cross-sectional research design was applied in this study. A longitudinal research design may help future researchers observe the causality relationship between empowering leadership, goal clarity, selfefficiency, and job performance. This study employed goal clarity and self-efficacy as mediator variables between empowering leadership and work performance. Future researchers can examine organizational culture as a moderating variable with this relationship. This study can be replicated in industrialized countries using the same variables. This study is only limited to the telecom sector; other sectors like health and education can be considered for future concerns. 
This study provides room for scholars and researchers to conduct this study with the relationship of the same variables in other sectors.

\section{Conclusions}

The primary objectives of the research were to investigate the relationship between empowering leadership, goal clarity, self-efficacy, and employees' job performance. The study's findings, empowering leadership positively and significantly affects job performance. Further, goal clarity and self-efficiency directly link with job performance. Additionally, goal clarity and self-efficacy improved the association between empowered leadership and job performance. The link between empowered leadership and job performance is strengthened when goal clarity and self-efficiency are mediators.

\section{References}

Abro, K. A., Siyal, A., Souayeh, B., \& Atangana, A. (2020). Application of statistical method on thermal resistance and conductance during magnetization of fractionalized free convection flow. International Communications in Heat and Mass Transfer, 119, 104971.

Afsar, B., Badir, Y. F., Saeed, B. B., \& Hafeez, S. (2017). Transformational and transactional leadership and employee's entrepreneurial behavior in knowledge-intensive industries. The International Journal of Human Resource Management, 28(2), 307-332.

Afsar, B., \& Masood, M. (2018). Transformational leadership, creative self-efficacy, trust in supervisor, uncertainty avoidance, and innovative work behavior of nurses. The Journal of Applied Behavioral Science, 54(1), 36-61.

Amundsen, S., \& Martinsen, Ø. L. (2015). Linking empowering leadership to job satisfaction, work effort, and creativity: The role of self-leadership and psychological empowerment. Journal of leadership E organizational Studies, 22(3), 304-323.

Andrews, R., \& Van de Walle, S. (2013). New public management and citizens' perceptions of local service efficiency, responsiveness, equity and effectiveness. Public Management Review, 15(5), 762-783.

Bakker, A. B., \& Albrecht, S. (2018). Work engagement: current trends. Career Development International.

Bandura, A. (2006). Guide for constructing self-efficacy scales. Self-efficacy beliefs of adolescents, 5(1), 307-337.

Beattie, S., Woodman, T., Fakehy, M., \& Dempsey, C. (2016). The role of performance feedback on the self-efficacy-performance relationship. Sport, Exercise, and Performance Psychology, $5(1), 1$.

Bowers, D. G., \& Seashore, S. E. (1966). Predicting organizational effectiveness with a four-factor theory of leadership. Administrative Science Quarterly, 238-263.

Bulgurcu, B., Cavusoglu, H., \& Benbasat, I. (2010). Information security policy compliance: an empirical study of rationality-based beliefs and information security awareness. MIS quarterly, 523-548. 
Byun, G., Lee, S., Karau, S. J., \& Dai, Y. (2020). The trickle-down effect of empowering leadership: a boundary condition of performance pressure. Leadership \& Organization Development Journal.

Caillier, J. G. (2016a). Does public service motivation mediate the relationship between goal clarity and both organizational commitment and extra-role behaviours? Public Management Review, 18(2), 300-318.

Caillier, J. G. (2016b). Linking transformational leadership to self-efficacy, extra-role behaviors, and turnover intentions in public agencies: The mediating role of goal clarity. Administration Eं Society, 48(7), 883-906.

Chan, S. C. (2019). Participative leadership and job satisfaction. Leadership \& Organization Development Journal.

Chiniara, M., \& Bentein, K. (2016). Linking servant leadership to individual performance: Differentiating the mediating role of autonomy, competence and relatedness need satisfaction. The Leadership Quarterly, 27(1), 124-141.

Choi, S. L., Goh, C. F., Adam, M. B. H., \& Tan, O. K. (2016). Transformational leadership, empowerment, and job satisfaction: the mediating role of employee empowerment. Human resources for health, 14(1), 1-14.

Chow, I. H. S. (2018). The mechanism underlying the empowering leadership-creativity relationship. Leadership \& Organization Development Journal.

Clausen, T., Meng, A., \& Borg, V. (2019). Does social capital in the workplace predict job performance, work engagement, and psychological well-being? A prospective analysis. Journal of occupational and environmental medicine, 61(10), 800-805.

Darvishmotevali, M., \& Ali, F. (2020). Job insecurity, subjective well-being and job performance: The moderating role of psychological capital. International Journal of Hospitality Management, 87, 102462.

Datu, J. A. D., Yuen, M., \& Chen, G. (2017). Development and validation of the Triarchic Model of Grit Scale (TMGS): Evidence from Filipino undergraduate students. Personality and Individual Differences, 114, 198-205.

Ebner, K., Schulte, E.-M., Soucek, R., \& Kauffeld, S. (2018). Coaching as stress-management intervention: The mediating role of self-efficacy in a framework of self-management and coping. International Journal of Stress Management, 25(3), 209.

Farhan, B. Y. (2017). Application of path-goal leadership theory and learning theory in a learning organization.

Gao, A., \& Jiang, J. (2019). Perceived empowering leadership, harmonious passion, and employee voice: the moderating role of job autonomy. Frontiers in psychology, 10, 1484.

Georgianna, S., Müller, G. F., Schermelleh-Engel, K., \& Petersen, B. (2016). Entrepreneurs' job satisfaction and its relationship to super-leadership and self-leadership. Journal of Research in Business, Economics and Management, 6(3), 928-940.

Gist, M. E. (1987). Self-efficacy: Implications for organizational behavior and human resource management. Academy of management review, 12(3), 472-485. 
Gonzalez-Mulé, E., Courtright, S. H., DeGeest, D., Seong, J.-Y., \& Hong, D.-S. (2016). Channeled autonomy: The joint effects of autonomy and feedback on team performance through organizational goal clarity. Journal of Management, 42(7), 2018-2033.

Gruman, J. A., \& Saks, A. M. (2011). Performance management and employee engagement. Human resource management review, 21(2), 123-136.

Haase, J., Hoff, E. V., Hanel, P. H., \& Innes-Ker, A. (2018). A meta-analysis of the relation between creative self-efficacy and different creativity measurements. Creativity Research Journal, $30(1), 1-16$.

Hair Jr, J. F., Sarstedt, M., Ringle, C. M., \& Gudergan, S. P. (2017). Advanced issues in partial least squares structural equation modeling: saGe publications.

Hao, P., He, W., \& Long, L.-R. (2018). Why and when empowering leadership has different effects on employee work performance: The pivotal roles of passion for work and role breadth self-efficacy. Journal of leadership E' organizational Studies, 25(1), 85-100.

Harman, H. H. (1976). Modern factor analysis: University of Chicago press.

Harris, T. B., Li, N., Boswell, W. R., Zhang, X. a., \& Xie, Z. (2014). Getting what's new from newcomers: Empowering leadership, creativity, and adjustment in the socialization context. Personnel Psychology, 67(3), 567-604.

Hoffmann, A. O., \& Plotkina, D. (2021). Positive framing when assessing the personal resources to manage one's finances increases consumers' retirement self-efficacy and improves retirement goal clarity. Psychology \& Marketing, 38(12), 2286-2304.

Hu, J., \& Liden, R. C. (2011). Antecedents of team potency and team effectiveness: An examination of goal and process clarity and servant leadership. Journal of applied psychology, 96(4), 851.

Humborstad, S. I. W., Nerstad, C. G., \& Dysvik, A. (2014). Empowering leadership, employee goal orientations and work performance: A competing hypothesis approach. Personnel Review.

Jaaffar, A. H., Ibrahim, H. I., Rajadurai, J., \& Sohail, M. S. (2019). Psychological impact of workintegrated learning programmes in malaysia: the moderating role of self-esteem on relation between self-efficacy and self-confidence. International Journal of Educational Psychology, 8(2), 188-213.

Jada, U. R., \& Mukhopadhyay, S. (2019). Understanding the effects of empowering, transformational and ethical leadership on promotive and prohibitive voice: A moderated mediated examination. Personnel Review.

Jaiswal, N. K., \& Dhar, R. L. (2015). Transformational leadership, innovation climate, creative self-efficacy and employee creativity: A multilevel study. International Journal of Hospitality Management, 51, 30-41.

Jamal, A. H., \& Ali, H. G. (2017). Mediating role of psychological empowerment between leadership empowerment behavior and job satisfaction: A study of telecom sector of Pakistan. Journal of the Research Society of Pakistan, 54(1).

Kim, E.-J., \& Park, S. (2020). Transformational leadership, knowledge sharing, organizational climate and learning: an empirical study. Leadership \& Organization Development Journal. 
Kim, J., Yammarino, F. J., Dionne, S. D., Eckardt, R., Cheong, M., Tsai, C.-Y., . . Park, J. W. (2020). State-of-the-science review of leader-follower dyads research. The Leadership Quarterly, 31(1), 101306.

Kim, M., \& Beehr, T. A. (2017). Self-efficacy and psychological ownership mediate the effects of empowering leadership on both good and bad employee behaviors. Journal of leadership \& organizational Studies, 24(4), 466-478.

Kim, M., \& Beehr, T. A. (2020). Empowering leadership: leading people to be present through affective organizational commitment? The International Journal of Human Resource Management, 31 (16), 2017-2044.

Kim, M., Beehr, T. A., \& Prewett, M. S. (2018). Employee responses to empowering leadership: A meta-analysis. Journal of leadership E organizational Studies, 25(3), 257-276.

Kirkman, B. L., \& Rosen, B. (1999). Beyond self-management: Antecedents and consequences of team empowerment. Academy of Management journal, 42(1), 58-74.

Kock, N. (2015). Common method bias in PLS-SEM: A full collinearity assessment approach. International Journal of e-Collaboration (ijec), $11(4), 1-10$.

Kundu, S. C., Kumar, S., \& Gahlawat, N. (2019). Empowering leadership and job performance: mediating role of psychological empowerment. Management Research Review.

Le, T. N., \& Nguyen, D. D. (2020). An impact of budgetary goal characteristics on performance: The case of Vietnamese SMEs. The Journal of Asian Finance, Economics, and Business, 7(9), 363-370.

Lee, A., Lyubovnikova, J., Tian, A. W., \& Knight, C. (2020). Servant leadership: A meta-analytic examination of incremental contribution, moderation, and mediation. Journal of Occupational and Organizational Psychology, 93(1), 1-44.

Lee, A., Willis, S., \& Tian, A. W. (2018). Empowering leadership: A meta-analytic examination of incremental contribution, mediation, and moderation. Journal of Organizational Behavior, 39(3), 306-325.

Li, H., Sajjad, N., Wang, Q., Muhammad Ali, A., Khaqan, Z., \& Amina, S. (2019). Influence of transformational leadership on employees' innovative work behavior in sustainable organizations: Test of mediation and moderation processes. Sustainability, 11(6), 1594.

Li, M., Liu, W., Han, Y., \& Zhang, P. (2016). Linking empowering leadership and changeoriented organizational citizenship behavior. Journal of Organizational Change Management.

Lix, L., \& Sajobi, T. (2010). Discriminant analysis for repeated measures data: a review. Frontiers in psychology, 1, 146.

Ma, Y., Cheng, W., Ribbens, B. A., \& Zhou, J. (2013). Linking ethical leadership to employee creativity: Knowledge sharing and self-efficacy as mediators. Social Behavior and Personality: an international journal, 41(9), 1409-1419.

Martin, S. L., Liao, H., \& Campbell, E. M. (2013). Directive versus empowering leadership: A field experiment comparing impacts on task proficiency and proactivity. Academy of Management journal, 56(5), 1372-1395.

Menguc, B., Auh, S., \& Uslu, A. (2013). Customer knowledge creation capability and performance in sales teams. Journal of the Academy of Marketing Science, 41(1), 19-39. 
Mueller, J., Renzl, B., \& Will, M. G. (2020). Ambidextrous leadership: A meta-review applying static and dynamic multi-level perspectives. Review of Managerial Science, 14(1), 37-59.

Na-Nan, K., Chaiprasit, K., \& Pukkeeree, P. (2018). Factor analysis-validated comprehensive employee job performance scale. International Journal of Quality \& Reliability Management.

Nalipay, M. J. N., \& Alfonso, M. K. S. (2018). Career and talent development self-efficacy of Filipino students: The role of self-compassion and hope. Philippine Journal of Psychology, 51(1), 101-120.

Naqshbandi, M. M., Tabche, I., \& Choudhary, N. (2019). Managing open innovation: The roles of empowering leadership and employee involvement climate. Management Decision.

O'Donoghue, D., \& van der Werff, L. (2021). Empowering leadership: balancing selfdetermination and accountability for motivation. Personnel Review.

Olafsen, A. H., Halvari, H., Forest, J., \& Deci, E. L. (2015). Show them the money? The role of pay, managerial need support, and justice in a self-determination theory model of intrinsic work motivation. Scandinavian journal of psychology, 56(4), 447-457.

Ostrom, A. L., Bitner, M. J., Brown, S. W., Burkhard, K. A., Goul, M., Smith-Daniels, V., ... . Rabinovich, E. (2010). Moving forward and making a difference: research priorities for the science of service. Journal of service research, 13(1), 4-36.

Oswald, T. M., Winder-Patel, B., Ruder, S., Xing, G., Stahmer, A., \& Solomon, M. (2018). A pilot randomized controlled trial of the ACCESS program: a group intervention to improve social, adaptive functioning, stress coping, and self-determination outcomes in young adults with autism spectrum disorder. Journal of autism and developmental disorders, 48(5), 1742-1760.

Patanakul, P., Pinto, J. K., \& Pinto, M. B. (2016). Motivation to perform in a multiple-project environment: The impact of autonomy, support, goal clarity, and opportunities for learning. Journal of Engineering and Technology Management, 39, 65-80.

Podsakoff, P. M., MacKenzie, S. B., Lee, J.-Y., \& Podsakoff, N. P. (2003). Common method biases in behavioral research: a critical review of the literature and recommended remedies. Journal of Applied psychology, 88(5), 879.

Qiu, M., Hu, B., Xu, Z., \& Li, Y. (2015). Employees' psychological ownership and self-efficacy as mediators between performance appraisal purpose and proactive behavior. Social Behavior and Personality: an international journal, 43(7), 1101-1109.

Ramirez, E., Gonzalez, R. J., \& Moreira, G. J. (2014). Barriers and bridges to the adoption of environmentally-sustainable offerings. Industrial Marketing Management, 43(1), 16-24.

Sariwulan, T., Agung, I., Sudrajat, U., \& Atmadiredja, G. (2019). The influence of job expectation, job satisfaction, and government policy towards the work stress, job enthusiasm and continuance commitment of the honorarium teacher. Jurnal Cakrawala Pendidikan, 38(2), 305-319.

Schunk, D. H., \& DiBenedetto, M. K. (2020). Motivation and social cognitive theory. Contemporary Educational Psychology, 60, 101832.

Schwarzer, R., \& Warner, L. M. (2013). Perceived self-efficacy and its relationship to resilience. In Resilience in children, adolescents, and adults (pp. 139-150): Springer. 
Shanafelt, T. D., \& Noseworthy, J. H. (2017). Executive leadership and physician well-being: nine organizational strategies to promote engagement and reduce burnout. Paper presented at the Mayo Clinic Proceedings.

Song, M., Meier, K. J., \& Amirkhanyan, A. (2020). Goal ambiguity, management, and performance in US nursing homes. Administration \& Society, 52(8), 1170-1208.

Srivastava, A., Bartol, K. M., \& Locke, E. A. (2006). Empowering leadership in management teams: Effects on knowledge sharing, efficacy, and performance. Academy of Management journal, 49(6), 1239-1251.

Stewart, H., \& Gapp, R. (2017). The role of organizational development in understanding leadership to achieve sustainability practices in small to medium enterprises. Organization Development Journal, 35(2), 33-57.

Tang, S., Zhang, G., \& Wang, H.-J. (2020). Daily Empowering Leadership and Job Crafting: Examining Moderators. International Journal of Environmental Research and Public Health, $17(16), 5756$.

Van der Hoek, M., Groeneveld, S., \& Kuipers, B. (2018). Goal setting in teams: Goal clarity and team performance in the public sector. Review of public personnel administration, 38(4), 472493.

Yilmaz, O. D. (2015). Revisiting the impact of perceived empowerment on job performance: Results from front-line employees. Turizam, 19(1), 34-46.

Zahra, T. T., Ahmad, H. M., \& Waheed, A. (2017). Impact of Ethical Leadership on Innovative Work Behavior: Mediating Role of Self-Efficacy. Journal of Behavioural Sciences, 27(1).

Zheng, X., Li, N., Brad Harris, T., \& Liao, H. (2019). Unspoken yet understood: An introduction and initial framework of subordinates' moqi with supervisors. Journal of Management, 45(3), 955-983.

Zhu, W., Sosik, J. J., Riggio, R. E., \& Yang, B. (2012). Relationships between transformational and active transactional leadership and followers' organizational identification: The role of psychological empowerment. Journal of Behavioral and Applied Management, 13(3), 168212.

Zimmerman, M. A. (2000). Empowerment theory. In Handbook of community psychology (pp. 4363): Springer.

\section{Appendix A}

Empowering Leadership (Kirkman \& Rosen, 1999)

1. Empowering leadership has set high standards for the performance of the Organization.

2. Empowering leadership process to promote hard work for the workgroup.

3. Empowering leadership provides a platform of an excellent example for the Organization's employees.

4. Empowering leadership encourages members of the workgroup to share their ideas and suggestions.

5. Empowering leadership pays attention to the views and suggestions of the group to make better decisions. 
6. Empowering Leadership assists group leaders in identifying areas where additional training is required.

7. Empowering leadership proposes strategies to increase the performance of the Organization's workgroup.

8. Empowering leadership showing Concern/Interacting with the team members.

Employees Job Performance (Na-Nan et al., 2018)

1. Are you currently satisfied with your performance at the job?

2. Did you talk to your boss about your performance last year?

3. DO you think that organisations support employees to show their skill and performance?

4. Are you personally supervised on your main job at the workplace?

5. Is the organisation management satisfied with your work at the workplace?

6. Do you think that your performance is higher than most workers on your job?

Goal Clarity (Patanakul, et al., 2016)

1. Do you think that Employees clearly understand their performance goals?

2. Can Employees' performance goals can be objectively measured.

3. Employees' performance goals are clearly ordered by their priority.

4. Employees' performance goals are appropriately aligned with organisational goals.

5. The reasons for an Employees' poor performance evaluation are clearly explained.

Self-Efficacy (Bandura, 2006)

1. If I work hard enough, I can always tackle challenging tasks.

2. Do you understand how to discover the means and strategies to get what you desire if someone opposes you?

3. Is it simple for you to connect with your goals to achieve the Organization's objectives?

4. Do you believe I would be able to deal effectively with unforeseen circumstances?

5. Do you know how to deal with unexpected events at work?

6. Do you believe that by putting in the most significant steps, you can solve complex problems?

6. Do you believe that we should remain calm in the face of adversity to take advantage of opportunities?

7. Do you believe you could easily handle all of the Organization's severe difficulties in order to achieve its goals? 